\title{
Microstructure and Fatigue Properties of AlZn6Mg0.8Zr Alloy Subjected to Low-Temperature Thermomechanical Processing
}

\author{
Aleksander Kowalski ${ }^{1}$, Wojciech Ozgowicz ${ }^{1}$, Adam Grajcar ${ }^{1, *}$, Marzena Lech-Grega ${ }^{2}$ \\ and Andrzej Kurek ${ }^{3}$ \\ 1 Silesian University of Technology, Institute of Engineering Materials and Biomaterials, \\ 44-100 Gliwice, Poland; kowalski.polsl@gmail.com (A.K.); wojciech.ozgowicz@polsl.pl (W.O.) \\ 2 Institute of Non-Ferrous Metals in Gliwice, Light Metals Division, 32-050 Skawina, Poland; \\ mlechgrega@imn.skawina.pl \\ 3 Opole University of Technology, Faculty of Mechanical Engineering, 45-271 Opole, Poland; \\ a.kurek@po.opole.pl \\ * Correspondence: adam.grajcar@polsl.pl; Tel.: +48-32-237-2940
}

Received: 22 August 2017; Accepted: 12 October 2017; Published: 21 October 2017

\begin{abstract}
The paper presents results of the investigations on the effect of the low-temperature thermomechanical treatment on the microstructure of AlZn6Mg0.8Zr alloy (7003 alloy) and the relationships between microstructure and fatigue properties and fractography of fractured samples. Fatigue life has been determined in a mechanical test at a simple state of loading under conditions of bending as well as torsion. The development of fatigue cracking has been described based on fractography investigations of the fractured samples making use of a scanning electron microscope (SEM). It was found that the factors determining the fatigue strength of the tested alloy are the microstructure as well as the type and size of the cyclic stresses. These factors determine the fractography of fatigue samples.
\end{abstract}

Keywords: aluminum alloy; 7003 alloy; fatigue properties; thermomechanical treatment; fractography

\section{Introduction}

Heat and thermomechanical processing of light metal alloys, particularly aluminum alloys for plastic working, is an effective way to increase their operating properties. Accelerated ageing process, connected with the impact of increased temperature and dependent on the rate of plastic deformation, mainly determines the microstructure of these alloys as well as the morphology and distribution of precipitations. Deformation of the material before ageing causes the precipitation becomes a competitive process between bulk precipitation and precipitation on dislocations. Moreover, microstructure evolution and mechanical properties depend on the sequence of the ageing and dynamics of phases formation after predeformation. It is important that the precipitates grow more slowly in the bulk than on dislocations. Therefore, it is necessary to consider each case individually and then it is possible to assess their synergistic effect during ageing. [1-3]. On the other hand, the grain size of the matrix of these alloys and the presence of strengthening intermetallic phases assure significant enhancement of their mechanical properties, and often also their ductile, fatigue and corrosion properties [4-6]. The attempts to prepare 7055 and 7075 aluminum alloys with such complex set of properties were noted in the work of Zuo et al. [7] and Das et al. [8].

The $\mathrm{Al}-\mathrm{Zn}-\mathrm{Mg}$ alloys (7000 series) are a relatively recent group of aluminum alloys applied in shipbuilding for construction of ships and displacement crafts, as well as high-speed surface effect vehicles, capable of transmitting high dynamic loads. The use of new constructional 
solutions and analytical methods for calculations of strength, based on technical stereomechanics for individual assemblies and ship structures, make modern high-speed fleet hulls approach more aircraft constructions rather than traditional naval solutions [9-11]. The 7000 series alloys, similarly to the 2000 series (Al-Li alloys) [12], are characterized by the highest strength among all aluminum alloy grades. However, this is dependent on properly performed heat and thermomechanical treatment as well as the obtained dispersion of precipitations both inside and on grain boundaries.

The knowledge of the fatigue characteristics of AlZn6Mg0.8Zr alloy (7003) is important due to varying loads of external forces, hydrodynamic loads in particular, and those caused by longitudinal bending moment, which are transferred by the bottom plating of high-speed surface effect vehicles. Many of these characteristics have not been reported in the literature, and most often there are data on the results of fatigue tests under cyclic tensile-compressive loads. Park, Jo et al. [13,14] determined the interaction of manganese-rich particles on the propagation of fatigue cracking of $\mathrm{Al}-\mathrm{Zn}-\mathrm{Mg}$ alloy during low-cycle fatigue. The influence of ageing conditions on fatigue properties of $\mathrm{Al}$ alloy with small concentration of Fe and Si admixtures (alloy 7475) has been investigated in [15]. Deng et al. [16] defined the fatigue strength of joints produced by the friction stir welding (FSW) of the 7050 aluminum alloy, while Effertz et al. [17] researched fatigue strength of joints of this alloy produced with friction spot welding (FSpW). The impact of secondary phase particles in the 7075 aluminum alloy, used for airplane wings components, as origins for fatigue cracking initiation as a function of the number of cycles was reported by Payne, Weiland et al. $[18,19]$. The attempts to simulate cracking initiation on the basis of these data were developed by Li et al. [20]. Zhao et al. [21] have tested the effects of stress ratio $(\mathrm{R})$, overloading, underloading, and high-low sequence loading on fatigue crack growth rate of the 7075 commercial alloy. Moreover, Zhao et al. [22] performed extensive studies on multiaxial fatigue load for the same alloy. Available literature is focused mostly on the 7000 series aluminum alloys with $\mathrm{Cu}$ addition, which leads to the increased corrosion of these alloys. Moreover, there are not many publications concerning bending and torsional fatigue loads. Therefore the purpose of undertaken studies was to determine the influence of diversified loading conditions during low- and high-cycle oscillatory bending and double-sided torsion on fatigue life and fatigue cracking resistance of the 7003 aluminum alloy without the addition of $\mathrm{Cu}$, after low temperature thermomechanical processing.

\section{Materials and Methods}

\subsection{Materials and Heat Treatment}

The study material was a metal sheet, cold-rolled from Al-Zn-Mg (7000 series) commercial aluminum alloy with a chemical composition is shown in Table 1.

Table 1. Chemical compositions of the investigated alloy.

\begin{tabular}{ccccccccccccccc}
\hline \multirow{2}{*}{$\begin{array}{c}\text { Denotation } \\
\text { of the Alloy }\end{array}$} & $\mathbf{Z n}$ & $\mathbf{M g}$ & $\mathbf{M n}$ & $\mathbf{F e}$ & $\mathbf{C r}$ & $\mathbf{S i}$ & $\mathbf{Z r}$ & $\mathbf{C u}$ & $\mathbf{G a}$ & $\mathbf{T i}$ & $\mathbf{N i}$ & $\mathbf{P b}$ & $\mathbf{A l}$ \\
\hline $\begin{array}{c}\text { EN AW-7003 } \\
\begin{array}{c}\text { EN AW-Al } \\
\text { Zn6Mg0.8Zr }\end{array}\end{array}$ & 6.134 & 0.742 & 0.291 & 0.197 & 0.167 & 0.121 & 0.080 & 0.036 & 0.005 & 0.005 & 0.004 & 0.003 & rest \\
\hline
\end{tabular}

The investigated alloy was subjected to a low-temperature thermomechanical treatment as shown in Figure 1:

- Preheated up to $500{ }^{\circ} \mathrm{C}$ and soaked for one hour,

- Cooled down in water,

- Cold-rolled with a degree of deformation of: $10 \%, 20 \%$ and $30 \%$,

- Aged for $12 \mathrm{~h}$ at a temperature of $150{ }^{\circ} \mathrm{C}$, then cooled down in the open air. 


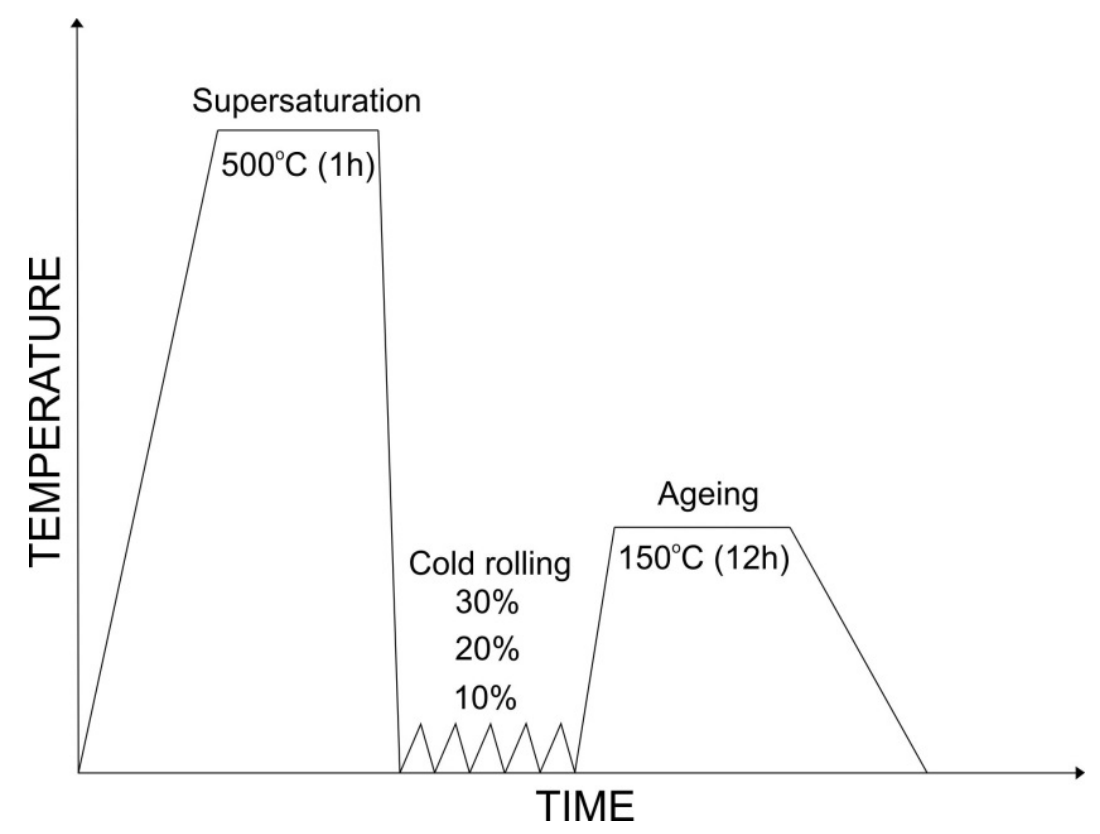

Figure 1. Scheme of low-temperature thermomechanical treatment of AlZn6Mg0.8Zr alloy.

Mechanical properties after the low-temperature thermomechanical treatment are presented in Table 2.

Table 2. Mechanical properties of the investigated alloy after the low-temperature thermomechanical treatment.

\begin{tabular}{|c|c|c|c|c|}
\hline \multirow[b]{2}{*}{$\begin{array}{c}\text { Degree of Deformation } \\
{[\%]}\end{array}$} & \multicolumn{4}{|c|}{ Mechanical Properties } \\
\hline & $\begin{array}{c}\overline{\mathrm{R}_{\mathrm{p} 0.2}} \\
{[\mathrm{MPa}]}\end{array}$ & $\begin{array}{c}\overline{\mathbf{R}_{\mathrm{m}}} \\
{[\mathrm{MPa}]}\end{array}$ & $\begin{array}{c}\overline{\mathbf{A}} \\
{[\%]}\end{array}$ & $\begin{array}{c}\overline{\mathrm{Z}} \\
{[\%]}\end{array}$ \\
\hline $10 \%$ & 256 & 321 & 10.2 & 49.5 \\
\hline $20 \%$ & 294 & 341 & 8.2 & 47.3 \\
\hline $30 \%$ & 300 & 347 & 9.1 & 40.4 \\
\hline Supersaturation $500{ }^{\circ} \mathrm{C} / 1 \mathrm{~h} /$ water & 174 & 313 & 19.8 & 25.0 \\
\hline
\end{tabular}

\subsection{Fatigue Tests}

The fatigue strength was tested on a test-stand MZGS-100 (Opole University of Technology, Faculty of Mechanical Engineering, Opole, Poland) [23] (Figure 2a) using un-notched standard samples (Figure $2 b$ ). The specimens were tested in two different stress conditions: oscillatory (cycling) bending and double-sided torsion under sinusoidally changing loading, both with a stress ratio $R=-1$ and a constant amplitude of bending or torsion moment $\left(\sigma_{\max }=\left|\sigma_{\min }\right|\right)$. The stress $\left(\sigma_{a}, \tau_{a}\right)$ amplitudes were calculated in the specimen area with a smallest diameter $(10 \mathrm{~mm})$ as a bending/torsion moment ratio to bending/torsional strength index, respectively. The stress concentration factor for the specimen geometry, especially for torsion, was calculated at a level of 1.03 and considered irrelevant for further studies. 


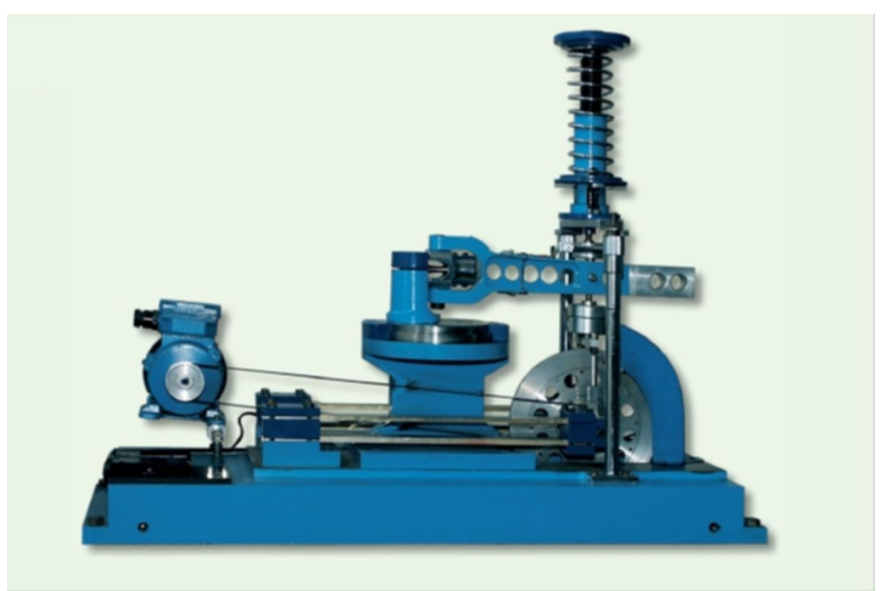

(a)

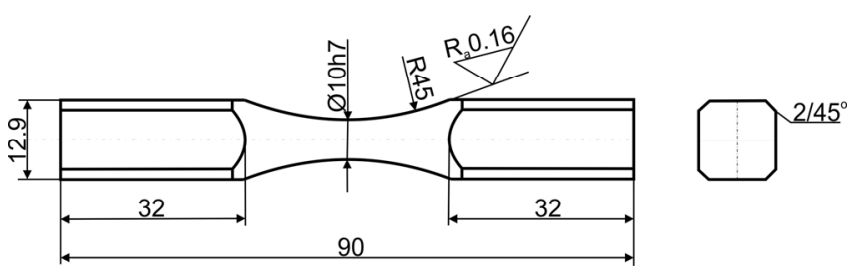

(b)

Figure 2. (a) Test stand MZGS-100 and (b) specimen for fatigue strength tests.

The tests were carried out at diversified intensity of stresses, ensuring low- and high-cycle fatigue of specimens. The results were plotted using the binary logarithmic system diagram $\log \left(\sigma_{\mathrm{a}}\right)$ vs. $\log \left(\mathrm{N}_{\mathrm{f}}\right)$ or $\log \left(\tau_{\mathrm{a}}\right)$ vs. $\log \left(\mathrm{N}_{\mathrm{f}}\right)$. The regression model was described with the following dependence:

$$
\mathrm{Y}=\mathrm{A}+\mathrm{mX}
$$

where: $\mathrm{Y}-\log \left(\sigma_{\mathrm{a}}\right)-\log$ arithm of normal or shearing stress- $\log \left(\tau_{\mathrm{a}}\right), \mathrm{X}-\log \left(\mathrm{N}_{\mathrm{f}}\right)-\operatorname{logarithm}$ of fatigue life, $\mathrm{m}$-directional coefficient.

The experimental results were approximated by the regression Equation (1) for bending and torsion in the form:

$$
\log \left(\mathrm{N}_{\mathrm{f}}\right)=\mathrm{A}_{\sigma}+\mathrm{m}_{\sigma} \log \left(\sigma_{\mathrm{a}}\right)
$$

and for double-sided torsion in the form:

$$
\log \left(\mathrm{N}_{\mathrm{f}}\right)=\mathrm{A}_{\tau}+\mathrm{m}_{\tau} \log \left(\tau_{\mathrm{a}}\right)
$$

where: $\mathrm{m}_{\sigma}, \mathrm{m}_{\tau}$-slope of regression line coefficients, $\mathrm{A}_{\sigma}, \mathrm{A}_{\tau}$-constant terms.

Fatigue tests of $\mathrm{AlZn} 6 \mathrm{Mg} 0.8 \mathrm{Zr}$ alloy were carried out on thermoplastically processed specimens, taking into consideration the number of fatigue cycles from approx. $2 \times 10^{4}$ to approx. $10^{7}$ and stress amplitude from 128 to $193 \mathrm{MPa}$ in case of oscillatory bending, and from 74 to 122 in case of double-sided torsion. The influence of low-temperature thermomechanical processing (LTMP) parameters on fatigue strength of the examined alloy was analyzed in relation to the supersaturated state. The basic parameter of the LTMP used in the comparative study of the temporary fatigue strength of examined alloy was the degree of cold deformation after supersaturation during LTMP.

\subsection{Metallographic Examinations}

Metallographic tests were carried out on microsections of longitudinal samples (Figure 3). The preparation of the microsections comprised standard operations of submerging the samples 
in chemohardened resin, grinding and mechanical polishing on a Struers LaboPol-21 machine (Struers Inc., Cleveland, $\mathrm{OH}, \mathrm{USA})$. The specimens for grain size observation were electrolytically etched in Barker's reagent. Observations of metallographic specimens using the polarized light were performed in the OLYMPUS GX-71 (Microscope Systems Limited, Glasgow, UK) light microscope, at magnifications of $500 \times$.

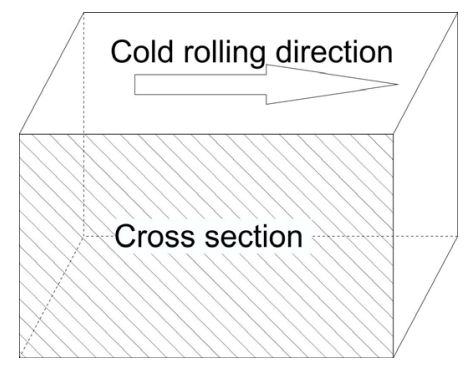

Figure 3. Cross section of longitudinal samples used in metallographic examinations.

\subsection{Fractographic Examinations}

Samples for fractographic investigations after bending and torsion tests were performed (Figure 4). For this purpose an electron-scanning microscope (SEM) of the ZEISS Supra 25-type (Carl Zeiss AG, Jena, Germany) was applied with an electron device GEMINI (Carl Zeiss AG, Jena, Germany) at a voltage of $20 \mathrm{kV}$. Comparisons of AlZn6Mg0.8Zr alloy fractures were done mainly due to the type of cyclically changing loads.

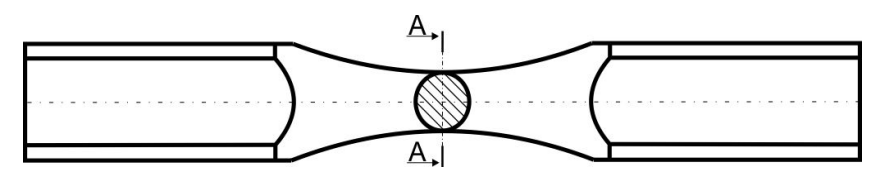

Figure 4. Cross section of fatigue samples used in fractographic observations.

\section{Results and Discussion}

\subsection{Fatigue Properties}

The values of coefficients in Equations (2) and (3) $\mathrm{m}_{\mathrm{B}, \mathrm{T}}$, and $\mathrm{A}_{\mathrm{B}, \mathrm{T}}$, are summarized in Table 3.

Table 3. Equation coefficients of regression lines for AlZn6Mg0.8Zr alloy after various stages of low-temperature thermomechanical processing (LTMP) and cyclic load tests.

\begin{tabular}{|c|c|c|c|c|}
\hline \multirow[t]{3}{*}{ Stage of LTMP } & \multicolumn{4}{|c|}{ Coefficient Value/Type of Load } \\
\hline & \multicolumn{2}{|c|}{ Bending } & \multicolumn{2}{|c|}{ Torsion } \\
\hline & $\mathrm{m}_{\mathrm{B}}$ & $\mathbf{A}_{\mathbf{B}}$ & $\mathrm{m}_{\mathrm{T}}$ & $\mathbf{A}_{\mathrm{T}}$ \\
\hline $\begin{array}{l}\text { Supersaturation } 500{ }^{\circ} \mathrm{C} \\
\text { Plastic deformation [\%] }\end{array}$ & -23.810 & 58.310 & -20.833 & 46.208 \\
\hline 10 & -27.778 & 67.694 & -15.625 & 36.500 \\
\hline 20 & -19.231 & 48.212 & -17.241 & 39.655 \\
\hline 30 & -38.462 & 91.192 & -20.833 & 46.854 \\
\hline
\end{tabular}

The AlZn6Mg0.8Zr alloy after supersaturation in water from the temperature of $500{ }^{\circ} \mathrm{C}$ in the LTMP, reveals the highest temporary fatigue strength for the analyzed range of load cycles in the oscillatory bending test (Figure 5). Loading of studied alloy with maximum bending stresses $\left(\sigma_{\mathrm{a}}\right)$ of $174 \mathrm{MPa}$ and torsional stresses $\left(\tau_{\mathrm{a}}\right)$ of $97 \mathrm{MPa}$ results in the failure of the sample at approx. $1.79 \times 10^{5}$ and $1.61 \times 10^{5}$, respectively. The high parallelism of regression lines was found for oscillatory bending and double-sided torsion in case of specimens supersaturated in water from the temperature of 
$500{ }^{\circ} \mathrm{C}\left(\mathrm{m}_{\mathrm{B}}=-23.810, \mathrm{~m}_{\mathrm{T}}=-20.833\right)$, suggesting a similar change of fatigue life along with increasing bending and torsion fatigue stresses (Table 3). The experimental data, obtained in case of fatigue loading of studied alloy with bending stresses after supersaturation from the temperature of $500{ }^{\circ} \mathrm{C}$, reveal small scatter of results $(S D=0.023)$, which demonstrates the high stability behavior of the tested alloy during stress changes $\sigma_{\mathrm{a}}$ as a function of the analyzed fatigue load cycles.

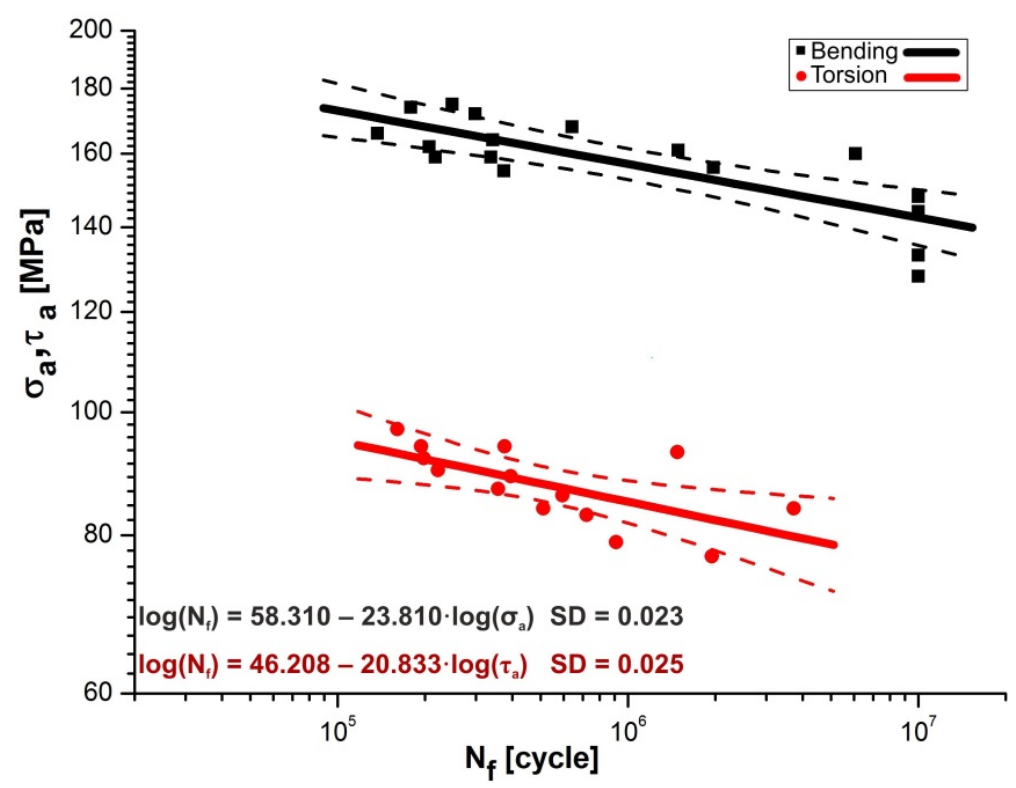

Figure 5. Basquin's characteristics of regression lines with confidence interval $(\alpha=0.05)$ for $\mathrm{AlZn6Mg0.8Zr}$ alloy after supersaturation in water from temperature of $500{ }^{\circ} \mathrm{C}$.

The course of temporary fatigue strength changes for tested alloy, subjected to LTMP with the deformation degree in the range (10-30)\% as a function of number of cycles and the load type (Figure 6), is similar to the one observed in case of supersaturation of the alloy in water from the temperature of $500{ }^{\circ} \mathrm{C}$ (Figure 5). The alloy subjected to the deformation of 10\% during LTMP exhibits fatigue life equal approx. $6.40 \times 10^{4}$ cycles at maximum bending stresses of $193 \mathrm{MPa}$, whereas in case of $30 \%$ deformation, loading of tested alloy with maximum bending stresses of $174 \mathrm{MPa}$ results in obtaining fatigue life of approx. $1.44 \times 10^{5}$ cycles. In case of torsional loads, the fatigue life for the alloy is equal about $2.70 \times 10^{4}$ cycles at maximum bending stresses of $122 \mathrm{MPa}$ for deformation of $10 \%$ and approx. $8.90 \times 10^{4}$ cycles at maximum stresses of $101 \mathrm{MPa}$ for $30 \%$ deformation during LTMP. Das et al. [8], while investigating the alloy of the same series (7075), characterized by higher concentration of $\mathrm{Mg}$ and the presence of $\mathrm{Cu}$, have noted an increase in fatigue life up to $70 \%$ for tensile-compressive loads along with increasing plastic strain at cryogenic temperature. The initial material, without deformation, revealed fatigue life for this type of load equal approx. $1.68 \times 10^{5}$ at maximum stresses of $240 \mathrm{MPa}$.

Minimal dispersion of experimental results was noted in case of cyclic bending loads. The standard deviation of regression lines (SD) for this type of load is the smaller the higher is the degree of deformation in the LTMP process. The value of SD for the degree of deformation of $10 \%$ to $30 \%$ changes from approximately 0.018 to about 0.005 , respectively (Figure 6 ). It was found that the value coefficients of regression lines $\mathrm{m}_{\mathrm{B}}$ and $\mathrm{m}_{\mathrm{T}}$ in case of the studied alloy subjected to LTMP with $20 \%$ degree of deformation (Figure $6 \mathrm{~b}$ ) are similar (in contrast to LTMP with $10 \%$ and $30 \%$ deformation degree) and they are -19.231 and -17.241 , respectively (Table 3 ). This allows to state that AlZn6Mg0.8Zr alloy, cold-rolled with 20\% deformation degree during LTMP, is characterized by a similar course of temporary fatigue strength under analyzed cyclically changing loads conditions. Moreover, regression lines in case of double-sided torsion of the examined alloy reveal high parallelism, irrespective of the degree of plastic deformation in the LTMP (Table 3). 


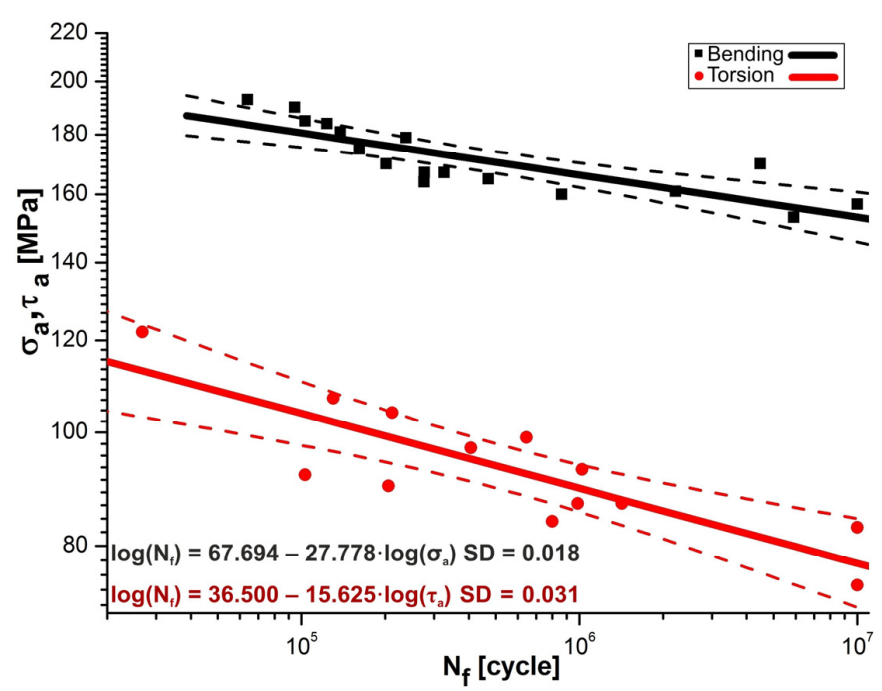

(a)

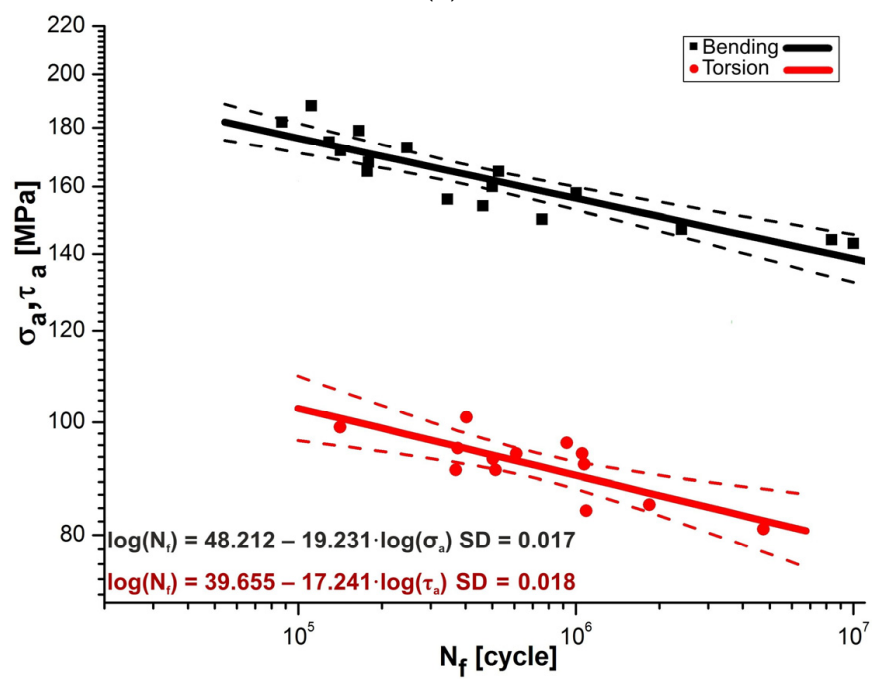

(b)

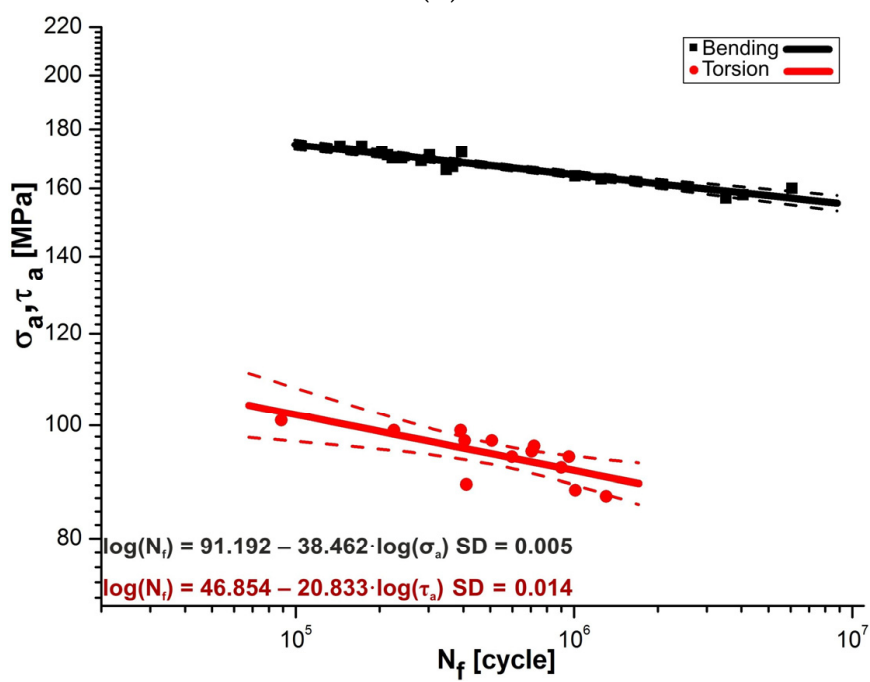

(c)

Figure 6. Basquin's characteristics of regression lines with confidence interval $(\alpha=0.05)$ for AlZn6Mg0.8Zr alloy subjected to cold rolling in LTMP with degree of deformation of: (a) $10 \%$; (b) $20 \%$ and (c) $30 \%$ after supersaturation from temperature of $500{ }^{\circ} \mathrm{C}$. 


\subsection{Microstructure after Low-Temperature Thermomechanical Processing}

Microstructure of AlZn6Mg0.8Zr alloy, subjected to supersaturation in water from $500{ }^{\circ} \mathrm{C}$ with subsequent rolling using $10 \%$ plastic deformation and ageing at the temperature of $150{ }^{\circ} \mathrm{C}$ for $12 \mathrm{~h}$, is characterized by a banding arrangement of grains of the $\alpha$ solution, inside which parallel slip bands and precipitations of primary phases have been observed (Figure 7a). Similar microstructure occurs for the $20 \%$ deformed alloy (Figure $7 \mathrm{~b}$ ). Plastic deformation of examined alloy with higher degree of cold work (30\%) during LTMP leads also to a banding system of grains in the $\alpha$ solution matrix, inside of which an increased amount of cold work symptoms are observed, most often as parallel slip bands (Figure 7c). It was found that the morphology and distribution of observed precipitations do not depend on the conditions of performed LTMP, which suggests that these are precipitations of primary phases. The microanalysis of chemical composition (using SEM) of dark points revealed mainly that these are Fe-rich phases, additionally suggesting that these are primary phases produced during casting process. The same observations were noted recently by Lech-Grega et al. [24], in the case of the 7020 aluminium alloy. The phases they observed contained Fe, Mn and Cr.

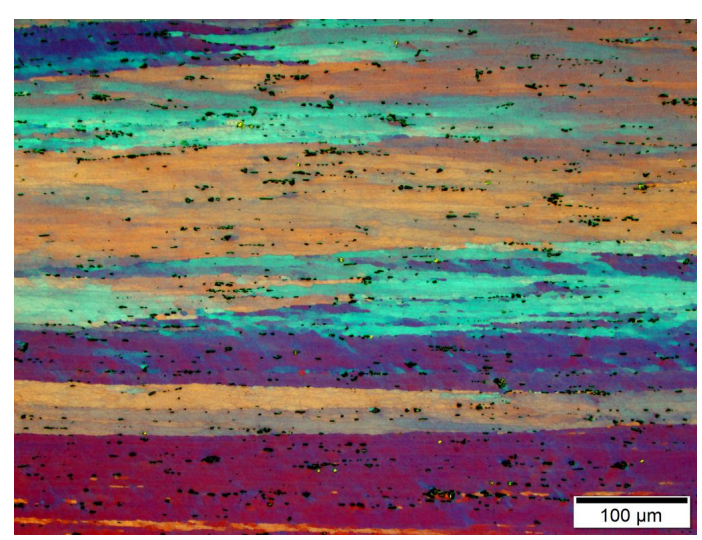

(a)

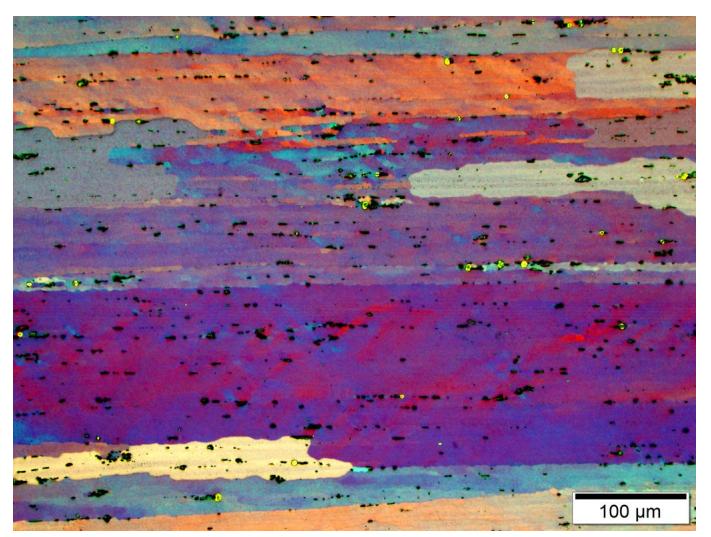

(b)

Figure 7. Cont. 


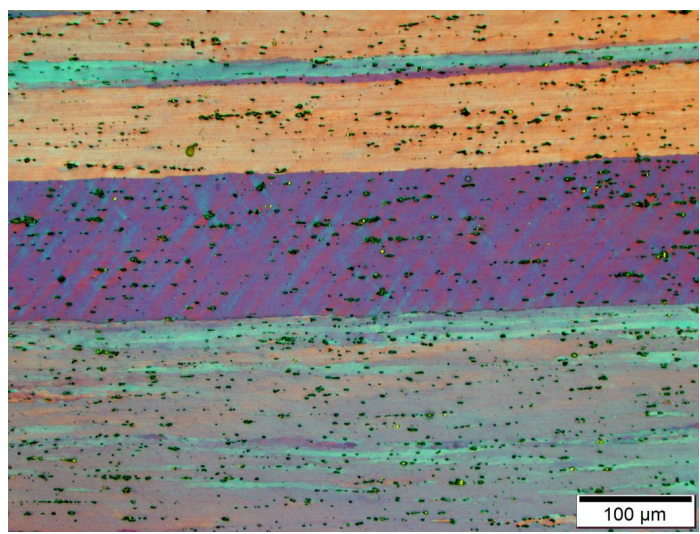

(c)

Figure 7. AlZn6Mg0.8Zr alloy subjected to LTMP with degree of deformation of: (a) $10 \%$; (b) $20 \%$; (c) $30 \%$.

\subsection{Fractography after Decohesion during Fatigue Tests}

During oscillatory bending tests of $\mathrm{AlZn} 6 \mathrm{Mg} 0.8 \mathrm{Zr}$ alloy samples, supersaturated in water from the temperature of $500{ }^{\circ} \mathrm{C}$, one can observe that the fractures analyzed in the range of low-cycle fatigue strength are primarily characterized by the presence of smooth surfaces of jogs of cleavage planes with locally occurring slight traces of plastic deformation (Figure 8a). Secondary fatigue cracks are also visible (Figure $8 \mathbf{b}$ ) as well as areas with mixed fracture characteristics (Figure 8c). The fractures of examined alloy in the range of high-cycle fatigue strength are quasi-cleavage with smooth surfaces of jogs of cleavage planes and cracks proceeding along these planes (Figure 8d).

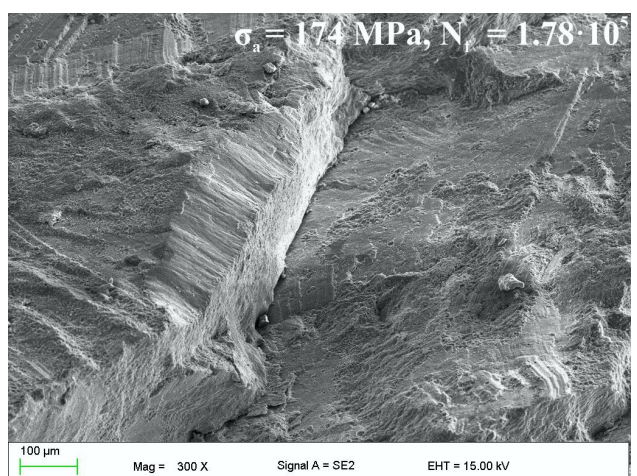

(a)

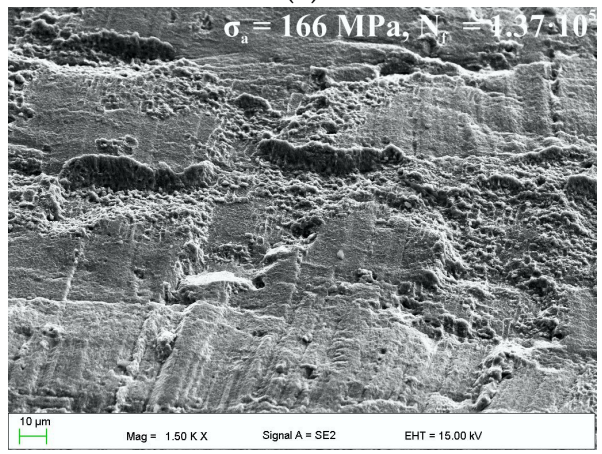

(c)

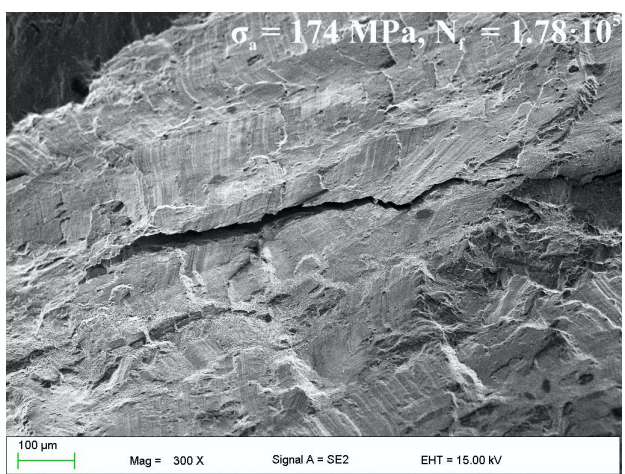

(b)

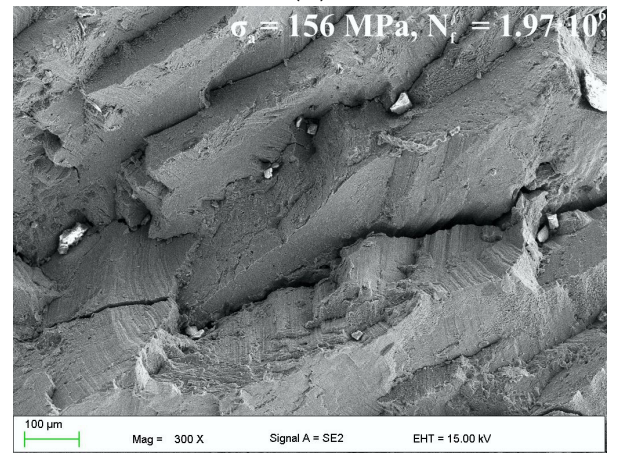

(d)

Figure 8. Fractures of fatigue test samples (oscillatory bending) of AlZn6Mg0.8Zr alloy, subjected to supersaturation in water from $500{ }^{\circ} \mathrm{C}$ : (a) smooth surfaces of jogs of cleavage planes; (b) secondary crack in the fracture surface; (c) mixed nature of the fracture; (d) cracks proceeding along the jogs of cleavage planes. 
The fractures of AlZn6Mg0.8Zr alloy, after supersaturation from the temperature of $500{ }^{\circ} \mathrm{C}$, subjected to double-sided torsion within the range of limited fatigue strength, are of the transcrystalline quasi-cleavage type with apparent slip bands systems on the cleavage planes, where secondary fatigue cracks proceeding along these bands can be also observed (Figure 9a). Moreover, differently oriented fatigue crack planes with irregular jogs and secondary fractures systems were revealed (Figure 9b,c). The areas with parallel slip bands on the cleavage planes are also typical (Figure 9d).

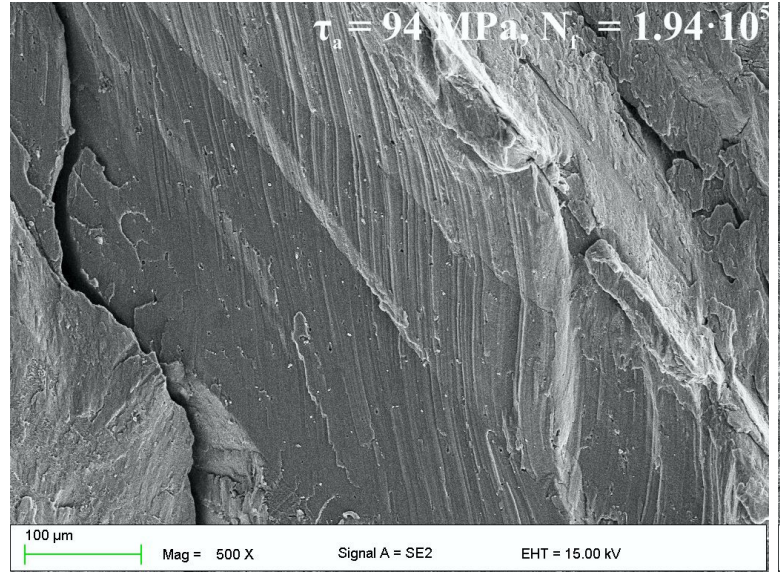

(a)

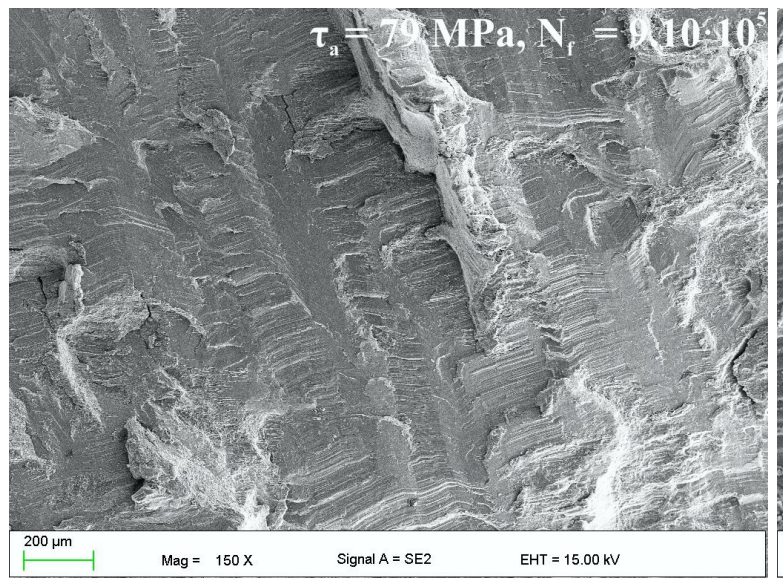

(c)

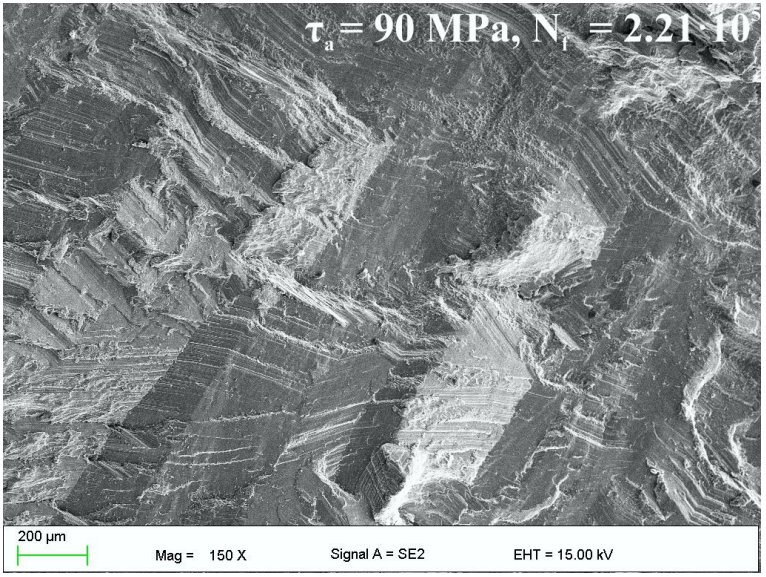

(b)

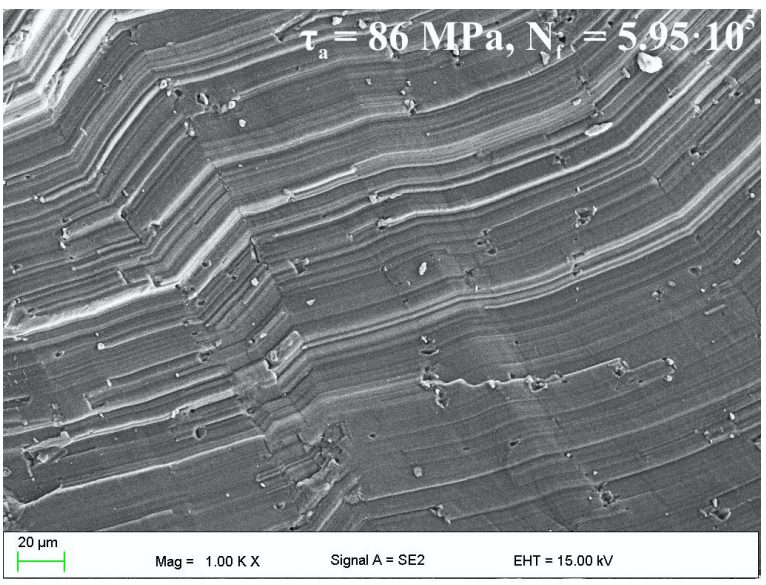

(d)

Figure 9. Fractures of fatigue test samples (double-sided torsion) of AlZn6Mg0.8Zr alloy, subjected to supersaturation in water from $500{ }^{\circ} \mathrm{C}$ : (a) secondary fatigue cracks along slip bands; (b) jogs of differently oriented fatigue crack planes; (c) jogs systems of cleavage planes; (d) parallel slip bands on the cleavage planes.

Fractures of studied alloy specimens after LTMP with the degree of deformation equal to $10 \%$, subjected to oscillatory bending with stress amplitude $\left(\sigma_{a}\right)$ in the range of low-cycle fatigue strength are of the transcrystalline quasi-cleavage type, with smooth jogs of cleavage planes with traces of plastic strain of the surface (Figure 10a). For specimens loaded with an amplitude of bending stress in the range of high-cycle fatigue strength, the presence of the origins of fatigue fractures with jogs of the transcrystalline-cleavage planes nature and numerous tongue-steps were observed in the surface area (Figure 10b). However, detailed microfractographic analysis of studied samples allows to state that observed transcrystalline quasi-cleavage fatigue fractures reveal local areas of plastic deformation on the jogs surfaces and traces of this deformation on potentially stochastic cleavage planes 
(Figure 10c). There are also often visible local material tears and cracks, probably of intercrystalline nature (Figure 10d).

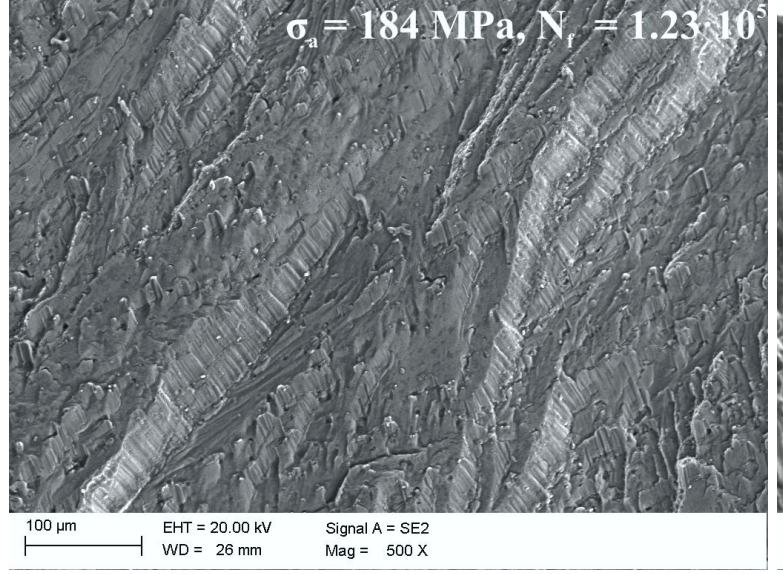

(a)

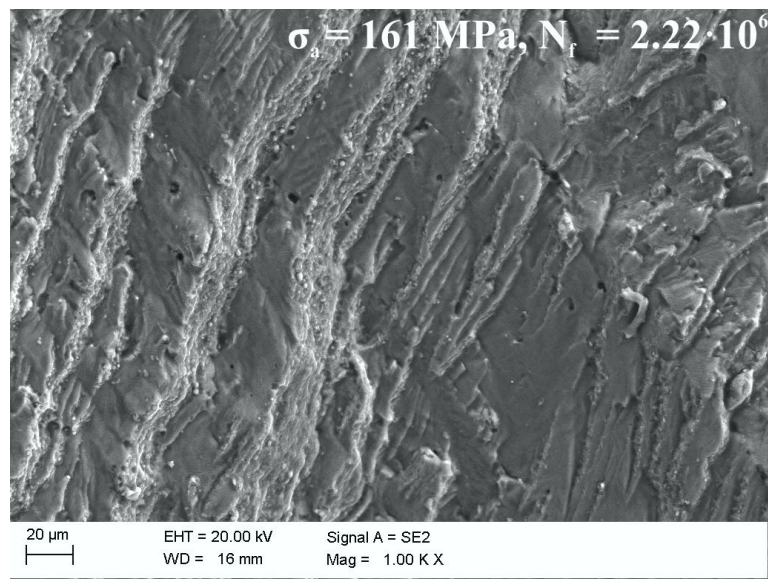

(c)

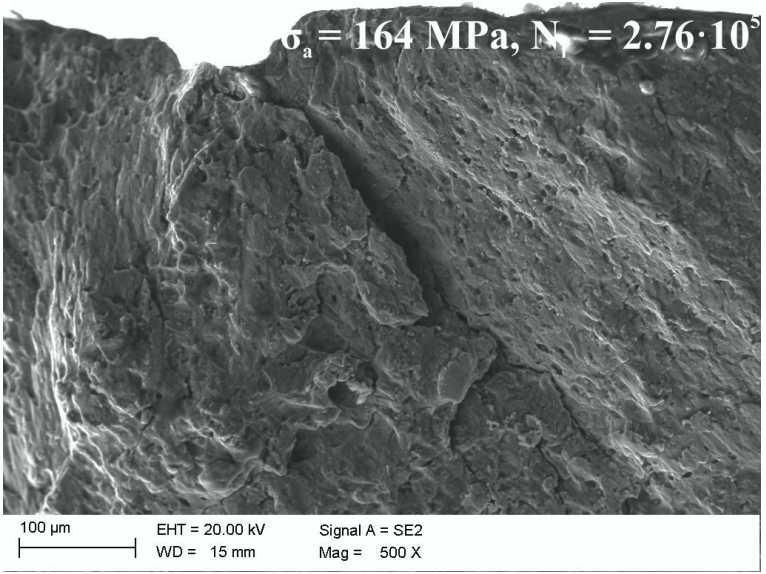

(b)

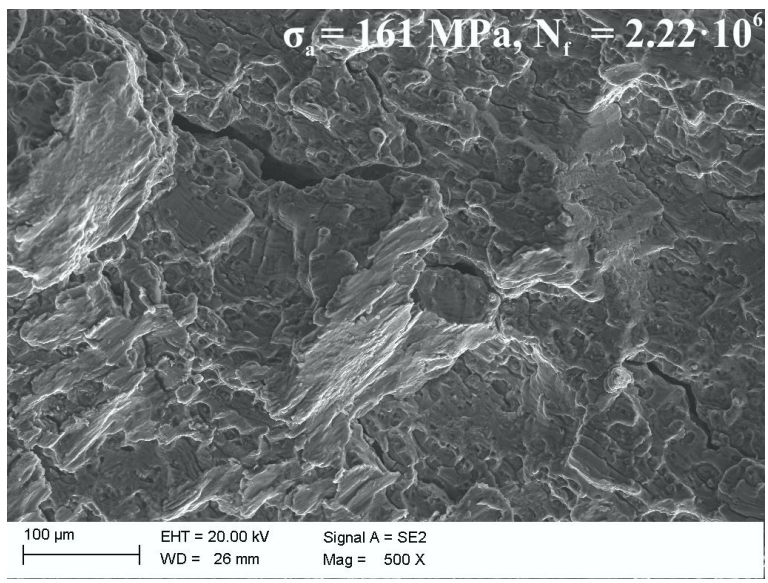

(d)

Figure 10. Fractures of fatigue test samples (oscillatory bending) of AlZn6Mg0.8Zr alloy, subjected to LTMP with 10\% degree of deformation: (a) traces of plastic deformation of the jogs surfaces of fatigue crack planes; (b) origins of fatigue fracture in the surface area; (c) traces of plastic deformation on the jogs surfaces of cleavage planes; (d) local material tears and cracks on the fatigue fracture surface.

Numerous secondary fatigue cracks of various length and depth are present on the fractures of investigated alloy, subjected to LTMP with $10 \%$ deformation after double-sided torsion, in the range of low-cycle fatigue strength (Figure 11a). Cracking initiation in these samples occurs in the surface zone where primary fatigue cracks and their origins were observed (Figure 11b). Irregularly arranged jogs of the cleavage planes were observed on the fractures of specimens subjected to double-sided torsion in the range of high-cycle fatigue strength (Figure 11c). Fatigue strips have been localized on surfaces of these jogs (Figure 11d). 


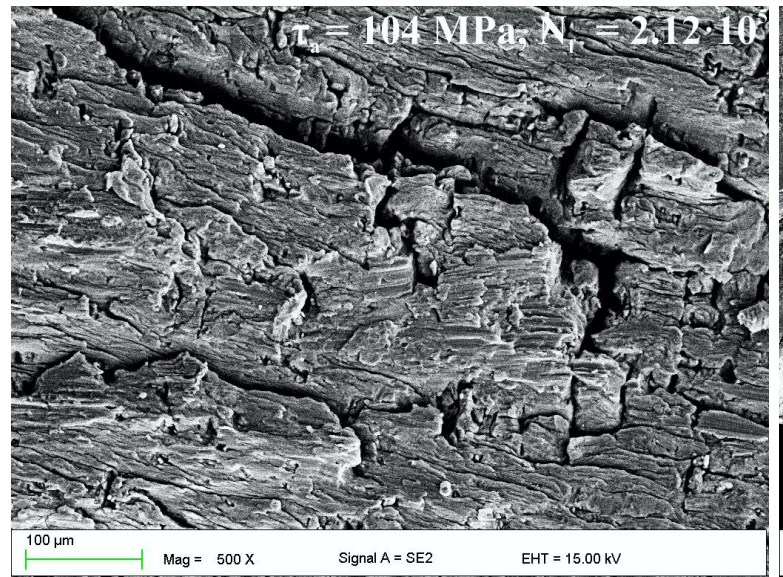

(a)

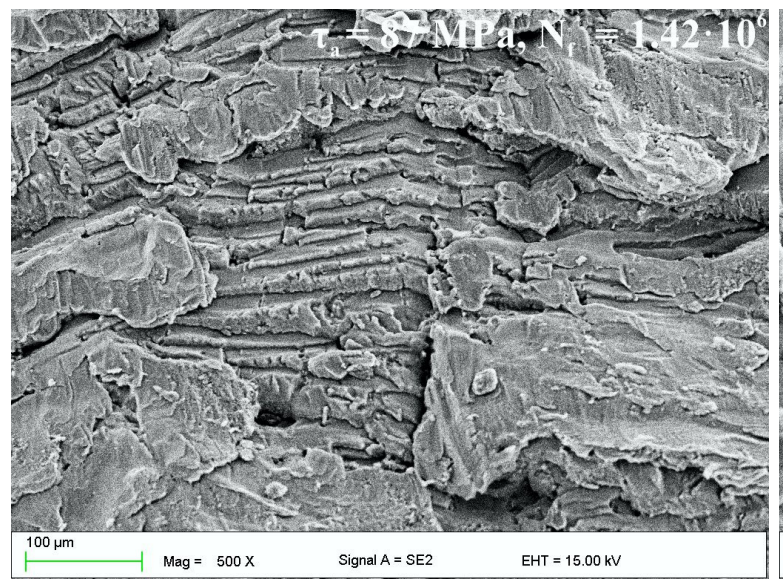

(c)

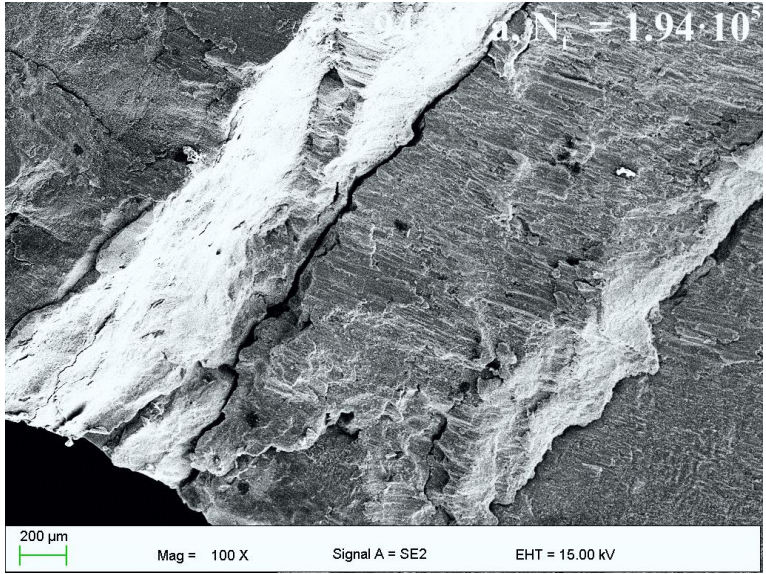

(b)

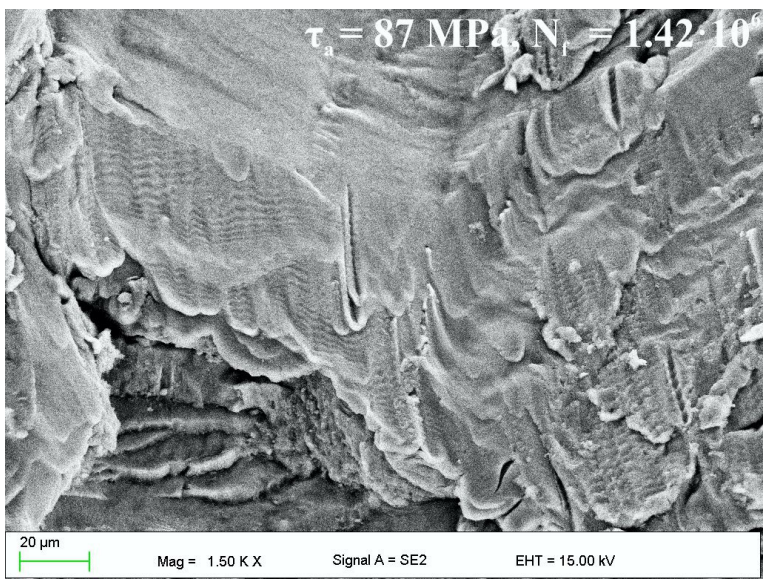

(d)

Figure 11. Fractures of fatigue test samples (double-sided torsion) of AlZn6Mg0.8Zr alloy, subjected to LTMP with $10 \%$ degree of deformation: (a) systems of secondary cracks on the cleavage planes; (b) focal point of fracture and primary fatigue crack on the specimen surface; (c) varied shape of jogs of the cleavage planes; (d) plastic fatigue strips on the jogs surface of crack planes.

The fractures of $\mathrm{AlZn} 6 \mathrm{Mg} 0.8 \mathrm{Zr}$ alloy specimens, subjected to LTMP with $30 \%$ cold rolling deformation after oscillatory bending with stress amplitude in the range of low-cycle fatigue strength, are of a transcrystalline quasi-cleavage nature (Figure 12a). Areas with the significant plastic deformation are observed in the form of plastic fatigue strips (Figure 12b). The occurrence of such effects of plastic deformation of fatigue fractures of the 7000 series alloy was also reported in [8]. However, Das et al. have observed these effects only in the range of high-cycle fatigue and not as in this case-in the whole examined range. It's possible that this is due to another type of load being applied (in [8] the samples were subjected to tensile-compressive stresses). In the vicinity of these strips, on the cleavage planes, secondary fatigue cracks were detected (Figure 12c). In addition, in the range of high-cycle fatigue strength, investigated alloy specimens exhibit the transcrystalline quasi-cleavage fracture with numerous jogs in the planes of cleavage, forming the systems of characteristic rivers and river basins (Figure 12d). 


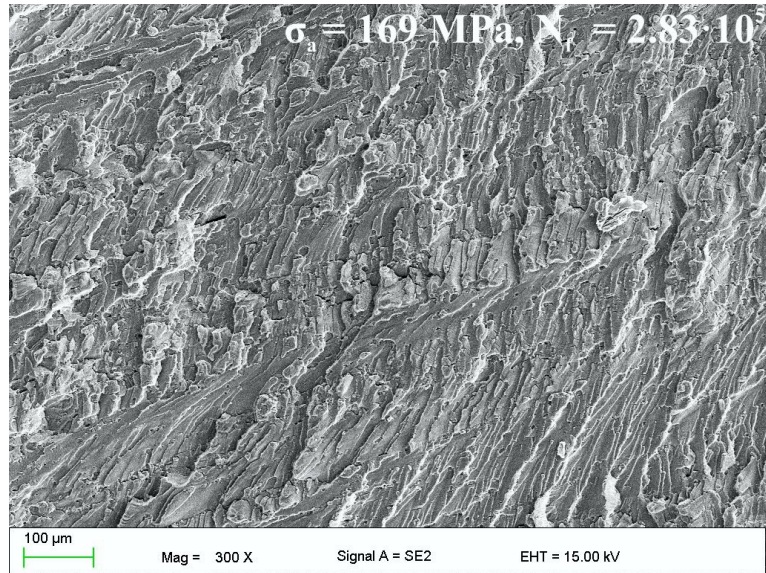

(a)

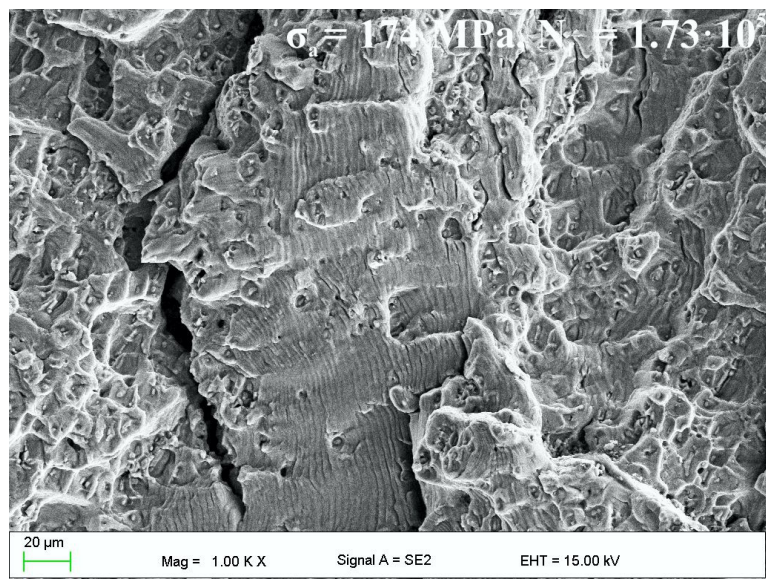

(c)

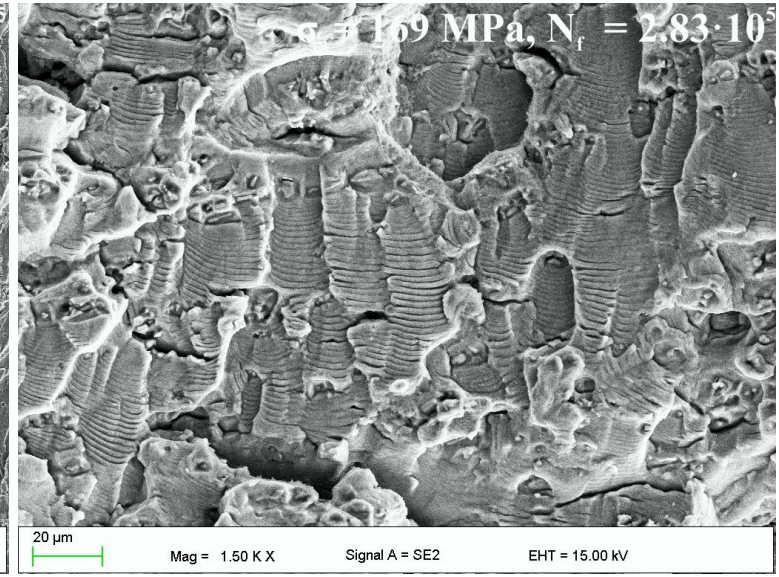

(b)

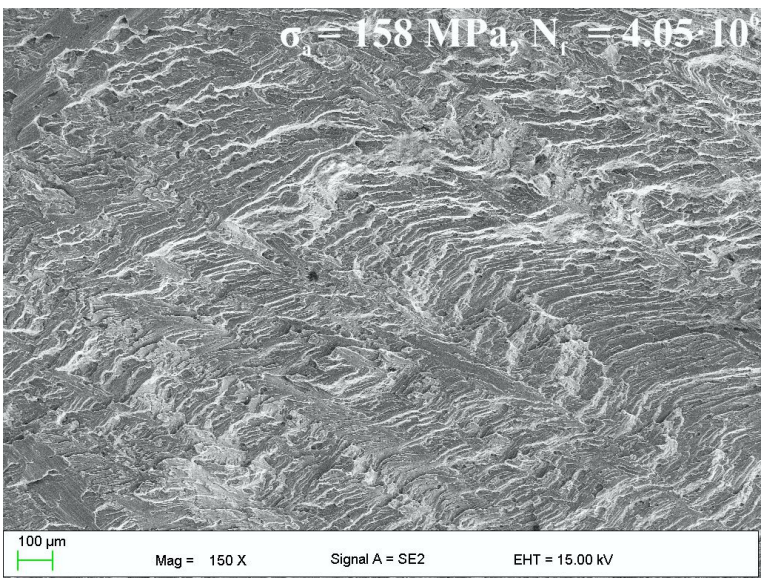

(d)

Figure 12. Fractures of fatigue test samples (oscillatory bending) of AlZn6Mg0.8Zr alloy, subjected to LTMP with 30\% degree of deformation: (a) quasi-cleavage character of the investigated alloy fracture; (b) fatigue strip systems on the surface of cleavage planes; (c) secondary crack and adjacent fatigue strips (d) jogs systems on the fatigue fracture surface of investigated alloy forming rivers and river basins.

The fractures of specimens from the alloy subjected to LTMP with a 30\% deformation degree reveal, after double-sided torsion with stress amplitude ( $\tau_{\mathrm{a}}$ approx. $\left.94-96\right)$ in the range of high number of cycles, transcrystalline quasi-cleavage nature with numerous fatigue cracks (Figure 13a) and craters of various size (Figure 13b). For the amplitude of torsional stress $\left(\tau_{\mathrm{a}}\right)$ in the range of (89-92) MPa, transcrystalline-cleavage fractures with extensive secondary cracks were detected (Figure 13c). Frequently, these cracks are spread in different directions, which may indicate the presence of a probable obstacle, e.g., in the form of precipitations, or the case where paths of cracks propagation run along grain boundaries (Figure 13d). Similar effects were observed by Park, Jo et al. in their works $[13,14]$. In Al-Zn-Mg alloy with $0.5 \%$ concentration of $\mathrm{Mn}$, the paths are different from those observed in alloys without this addition. The Mn-rich dispersive phases act as hindrances and lead to refraction of cracking paths, so that they become more "tortuous". Moreover, they found that fine Mn-rich particles, present in Al-Zn-Mg-(Mn) alloy, cause both increased low-cycle fatigue strength and crack toughness. Payne et al. [18] found that phase particles (e.g., $\mathrm{Al}_{7} \mathrm{Cu}_{2} \mathrm{Fe}$ ), which are harder than the matrix, become the precursors of cracking and when the number of fatigue cycles increase, 
they lead to propagation of cracking in the alloy matrix. On the other hand, the particles with hardness smaller than the matrix (e.g., $\mathrm{Mg}_{2} \mathrm{Si}$ ) are not often privileged areas for initiation of cracks.

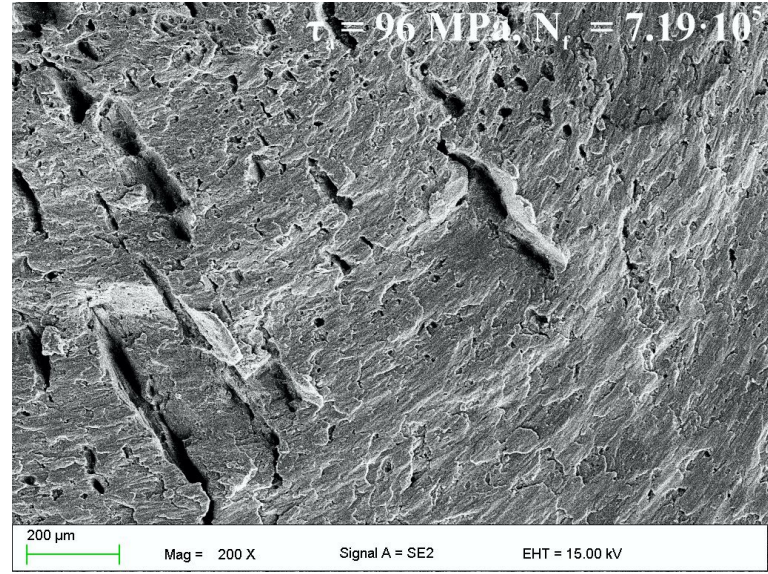

(a)

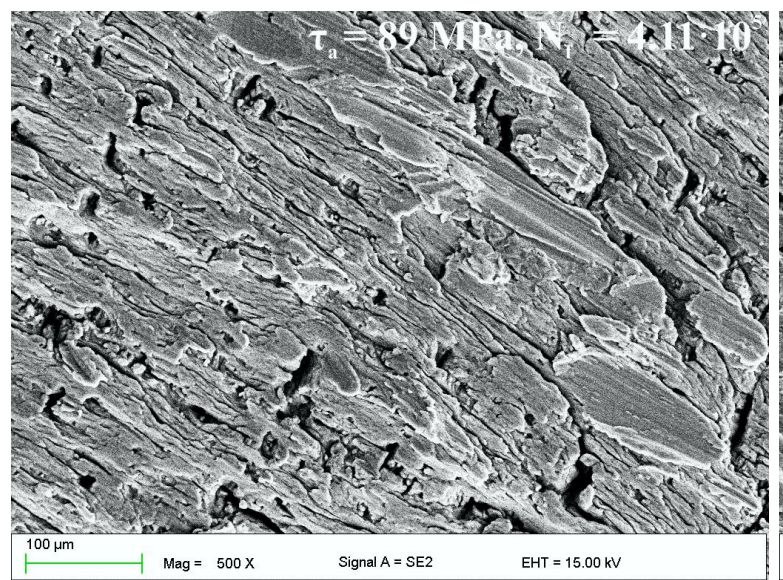

(c)

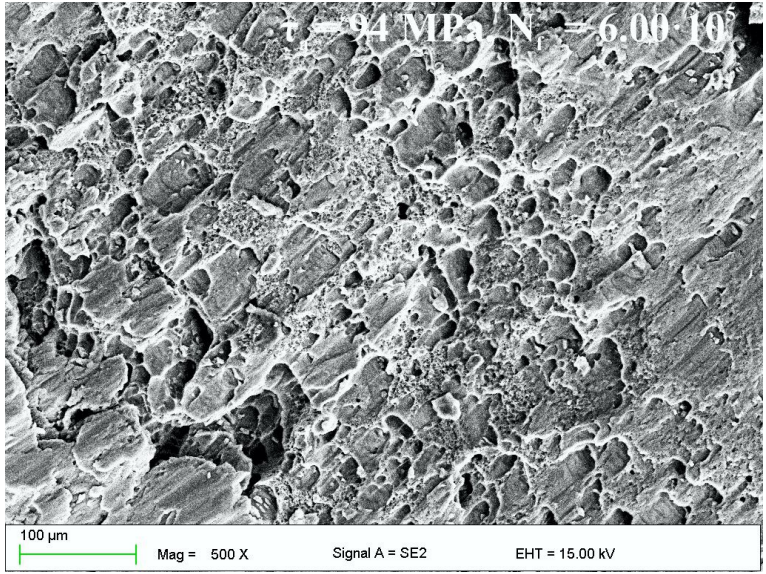

(b)

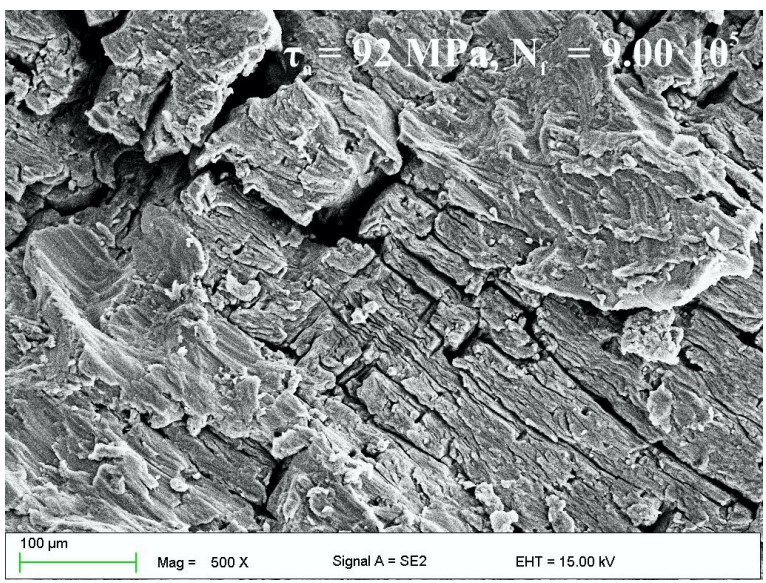

(d)

Figure 13. Fractures of fatigue test samples (double-sided torsion) of AlZn6Mg0.8Zr alloy, subjected to LTMP with $30 \%$ degree of deformation: (a) transcrystalline quasi-cleavage fracture with secondary cracks; (b) craters with diversified size on the fracture surface; (c) secondary cracks systems on the fatigue fracture surface of investigated alloy; (d) secondary cracks of deep depth on the fracture surface.

Increasing the degree of plastic deformation from 10\% to 30\% during LTMP results in increasing number of fracture areas with traces of plastic deformation, especially on the surface of cleavage planes. This is particularly evident in case of oscillatory bending. However, it does not result in an absolute increase of fatigue strength, but it affects the lower slope of the regression line. This observation allows us to assert that plastic deformation has a beneficial effect on the temporary fatigue strength of these alloys. Reducing the slope of the regression lines evidences greater homogeneity of the alloy 7003 during increasing fatigue load, both in the case of bending and torsion stresses.

\section{Conclusions}

The performed fatigue tests of the 7003 series $\mathrm{Al}-\mathrm{Zn}-\mathrm{Mg}$ alloy and metallographic analysis allow to formulate the following conclusions:

- $\quad \mathrm{AlZn} 6 \mathrm{Mg} 0.8 \mathrm{Zr}$ alloy exhibits higher temporary fatigue strength in case of cyclic bending loads compared to torsion loads, regardless of state of the material. 
- Investigated alloy, subjected to fatigue stresses from bending and torsion demonstrates more uniform course of temporary fatigue strength in case of oscillatory bending, determined statistically in the analyzed range of loads.

- It has been found that the important factors determining the portion of transcrystalline quasi-cleavage and ductile fractures are mainly: material state, type of applied fatigue load and amplitude of stress, and conditioning the number of cycles leading to failure.

- Increase in the degree of plastic deformation in the range from 10 to $30 \%$ results in an increase of the area of ductile fracture, which causes greater homogeneity of the 7003 alloy during increasing bending and torsion fatigue loads.

Acknowledgments: The publication is partially supported by the rector grant in the area of scientific research and development works. Silesian University of Technology, No. 10/010/RGJ17/0143.

Author Contributions: Aleksander Kowalski and Wojciech Ozgowicz conceived and designed the experiments; Aleksander Kowalski performed fractographic observations, analyzed the data and wrote the paper; Wojciech Ozgowicz supervised the work; Adam Grajcar analyzed the data and reviewed the paper; Marzena Lech-Grega performed metallographic experiments and analyzed the results; Andrzej Kurek performed fatigue tests and analyzed the results; all authors discussed the paper.

Conflicts of Interest: The authors declare no conflicts of interest.

\section{References}

1. Ferragut, R.; Somoza, A.; Tolley, A.; Torriani, I. Precipitation kinetics in Al-Zn-Mg commercial alloys. J. Mater. Process. Technol. 2003, 141, 35-40. [CrossRef]

2. Thomson, D.S.; Subramanya, B.S.; Levy, S.A. Quench rate effects in Al-Zn-Mg-Cu alloys. Metall. Trans. 1971, 2,1149-1160. [CrossRef]

3. Deschamps, A.; Livet, F.; Bréchet, Y. Influence of predeformation on ageing in an Al-Zn-Mg alloy-I. Microstructure evolution and mechanical properties. Acta Mater. 1998, 47, 281-292.

4. Deschamps, A.; Bréchet, Y. Influence of quench and heating rates on the ageing response of an $\mathrm{Al}-\mathrm{Zn}-\mathrm{Mg}-(\mathrm{Zr})$ alloy. Mater. Sci. Eng. A 1998, 251, 200-207. [CrossRef]

5. Chemingui, M.; Khitouni, M.; Jozwiak, K.; Mesmacque, G.; Kolsi, A. Characterization of the mechanical properties changes in an $\mathrm{Al}-\mathrm{Zn}-\mathrm{Mg}$ alloy after a two-step ageing treatment at $70{ }^{\circ} \mathrm{C}$ and $135^{\circ} \mathrm{C}$. Mater. Design 2010, 31, 3134-3139. [CrossRef]

6. Hoyt, J. On the coarsening of precipitates located on grain boundaries and dislocations. Acta Metall. Mater. 1991, 39, 2091-2098. [CrossRef]

7. Zuo, J.; Hou, L.; Shi, J.; Cui, H.; Zhuang, L.; Zhang, J. Effect of deformation induced precipitation on dynamic aging process and improvement of mechanical/corrosion properties AA7055 aluminum alloy. J. Alloys Comp.. [CrossRef]

8. Das, P.; Jayaganthan, R.; Chowdhury, T.; Singh, I.V. Fatigue behaviour and crack growth rate of cryorolled Al 7075 alloy. Mater. Sci. Eng. A 2011, 528, 7124-7132. [CrossRef]

9. Heinz, A.; Haszler, A.; Keidel, C.; Moldenhauer, S.; Benedictus, R.; Miller, W.S. Recent development in aluminium alloys for aerospace applications. Mater. Sci. Eng. A 2000, 280, 102-107. [CrossRef]

10. Williams, J.C.; Starke, E.A., Jr. Progress in structural materials for aerospace systems. Acta Mater. 2003, 51, 5775-5799. [CrossRef]

11. Shizhen, W.; Cuiyun, L.; Ruolin, W.; Chaoli, M. Effect of cold expansion on high cycle fatigue of 7A85 aluminum alloy straight lugs. Rare Metal Mater. Eng. 2015, 44, 2358-2362. [CrossRef]

12. Dursun, T.; Soutis, C. Recent developments in advanced aircraft aluminium alloys. Mater. Design 2014, 56, 862-871. [CrossRef]

13. Park, D.S.; Kong, B.O.; Nam, S.W. Effect of Mn-dispersoid on the low-cycle fatigue life of Al-Zn-Mg alloys. Metall. Mater. Trans. A 1994, 25, 1547-1550. [CrossRef]

14. Jo, B.L.; Park, D.S.; Nam, S.W. Effect of Mn dispersoid on the fatigue crack propagation of Al-Zn-Mg alloys. Metall. Mater. Trans. A 1996, 27, 490-493. [CrossRef]

15. Gürbüz, R.; Sarioğlu, F. Fatigue crack growth behavior in aluminium alloy 7475 under different aging conditions. Mater. Sci. Technol. Ser. 2001, 17, 1539-1543. [CrossRef] 
16. Deng, C.; Wang, H.; Gong, B.; Li, X.; Lei, Z. Effects of microstructural heterogeneity on very high cycle fatigue properties of 7050-T7451 aluminum alloy friction stir butt welds. Int. J. Fatigue 2016, 83, 100-108. [CrossRef]

17. Effertz, P.S.; Infante, V.; Quintino, L.; Suhuddin, U.; Hanke, S.; dos Santos, J.F. Fatigue life assessment of friction spot welded 7050-T76 aluminium alloy using Weibull distribution. Int. J. Fatigue 2016, 87, 381-390. [CrossRef]

18. Payne, J.; Welsh, G.; Christ, R.J., Jr.; Nardiello, J.; Papazian, J.M. Observations of fatigue crack initiation in 7075-T651. Int. J. Fatigue 2010, 32, 247-255. [CrossRef]

19. Weiland, H.; Nardiello, J.; Zaefferer, S.; Cheong, S.; Papazian, J.; Raabe, D. Microstructural aspects of crack nucleation during cyclic loading of AA7075-T651. Eng. Fract. Mech. 2009, 76, 709-714. [CrossRef]

20. Li, L.; Shen, L.; Proust, G. Fatigue crack initiation life prediction for aluminium alloy 7075 using crystal plasticity finite element simulations. Mech. Mater. 2015, 81, 84-93. [CrossRef]

21. Zhao, T.; Zhang, J.; Jiang, Y. A study of fatigue crack growth of 7075-T651 aluminum alloy. Int. J. Fatigue 2008, 30, 1169-1180. [CrossRef]

22. Zhao, T.; Jiang, Y. Fatigue of 7075-T651 aluminum alloy. Int. J. Fatigue 2008, 30, 834-849. [CrossRef]

23. Kurek, A.; Wachowski, M.; Niesłony, A.; Płociński, T.; Kurzydłowski, K.J. Fatigue tests and metallographic of explosively cladded steel-titanium bimetal. Arch. Metall. Mater. 2014, 59, 1565-1570. [CrossRef]

24. Lech-Grega, M.; Hawryłkiewicz, S.; Richert, M.; Szymański, W. Structural parameters of 7020 alloy after heat treatment simulating the welding process. Mater. Charact. 2001, 46, 251-257. [CrossRef]

(C) 2017 by the authors. Licensee MDPI, Basel, Switzerland. This article is an open access article distributed under the terms and conditions of the Creative Commons Attribution (CC BY) license (http:/ / creativecommons.org/licenses/by/4.0/). 